\title{
MORPHOMETRIC ANALYSIS OF SUPERIOR ARTICULAR FACETS OF ATLAS VERTEBRA AND ITS CLINICAL APPLICATIONS
}

\author{
Parineeta Suman', Laxmi Chettangada Cariappa², Raj Kishore Mahato ${ }^{3}$
}

${ }^{1}$ Assistant Professor, Department of Anatomy, Velammal Medical College Hospital \& Research Institute, Madurai. ${ }^{2}$ Associate Professor, Department of Physiology, Velammal Medical College Hospital \& Research Institute, Madurai. 3 Professor, Department of Pharmacology, Velammal Medical College Hospital \& Research Institute, Madurai.

\section{ABSTRACT}

\section{BACKGROUND}

The anatomy of the atlas vertebra reveals complex, three-dimensional structures, showing extensive variability in morphology. The large number of variations seen in the shape, size and depth of the superior articular facets of the atlas vertebrae indicate that the atlanto-occipital joint is correspondingly variable. Features of the atlas vertebra must be familiar before any spinal surgeries.

The objectives of the present study were to report the analysed morphological features and metrical values of superior articular facets of atlas vertebra.

\section{MATERIALS AND METHODS}

The study was carried out on 32 (64 sides) dried specimens of atlas vertebrae for variability in shape due to presence of constriction and partial or complete separation of superior articular facets. Superior articular facets of the vertebrae were measured for dimension, using Vernier calliper and any abnormalities present in it were noted down and photographed. Intact human atlases from the dissected cadavers were utilised but broken, undeveloped, porous macerated bones (atlas vertebrae) were also excluded from the study.

Statistical analyses of the measurements were done.

\section{RESULTS}

Oval, kidney, dumb bell, figure of eight and trilobed shapes were observed either on both sides or on one side. Commonest shape of superior articular facet was oval in $40.62 \%$ of specimens. On right side, the average length was 20.3 mm \& breadth was 11.7 $\mathrm{mm}$. On left side, the average length was $21 \mathrm{~mm}$ \& breadth was $11.05 \mathrm{~mm}$. Complete separation of facets was seen in $3.12 \%$ of vertebrae.

\section{CONCLUSION}

The knowledge of these measurements and the variations present may be of importance to understand the ergonomics of the craniovertebral joint and they are helpful for orthopaedic surgeons, neurosurgeons, clinicians and radiologists in day-to-day clinical practice.

\section{KEYWORDS}

Superior Articular Facet, Atlas, Vertebra.

HOW TO CITE THIS ARTICLE: Suman P, Cariappa LC, Mahato RK. Morphometric analysis of superior articular facets of atlas vertebra and its clinical applications. J. Evolution Med. Dent. Sci. 2017;6(69):4912-4916, D0I: 10.14260/Jemds/2017/1065

\section{BACKGROUND}

The first cervical vertebra, namely the atlas (C1) is a ringshaped unique vertebra and has different anatomical features from other cervical vertebrae. It (C1) holds the globe of the skull and is devoid of body and spine. It has two lateral masses linked by an anterior and posterior arch. The posterior arch of the atlas forms about $3 / 5^{\text {th }}$ of the atlantal ring. ${ }^{[1,2]}$

Superior Articular Facets (SAF) are present on atlas vertebra facing superomedially and they occupy most of the upper surface of the lateral mass and lie obliquely, their anterior ends being always nearer to the midline than the

Financial or Other, Competing Interest: None.

Submission 24-07-2017, Peer Review 17-08-2017,

Acceptance 23-08-2017, Published 28-08-2017.

Corresponding Author:

Dr. Parineeta Suman,

2C Kaveri Block,

Velammal Medical College,

Anuppanadi, Madurai-625009, Tamilnadu.

E-mail: parineeta_suman@rediffmail.com

DOI: $10.14260 /$ jemds $/ 2017 / 1065$ posterior ends. Facets are usually concave, with concavity in both longitudinal and transverse directions. The facets form an atlanto-occipital joint with occipital condyles and this joint is responsible for nodding movements and also for the weightbearing of the head. The atlanto-occipital joint strains predominantly induce a tension-like headache which is caused as a result of a prolonged and an inappropriate posture which results from a poor ergonomic adaptation. Cervical spine malformations and craniovertebral junction abnormalities which lead to hypermobility of atlantooccipital joints, give rise to neurological and vascular symptoms.[1,3,4] It has been postulated that anteroposterior axial changes are important for assessing the surgical applications.

The anatomy of the atlas vertebra reveals complex, threedimensional structures, showing extensive variability in morphology. Features of the atlas vertebra must be familiar before any spinal surgeries. So the objectives of the present study were to report the analysed morphological features and metrical values of superior articular facets of atlas vertebra. 


\section{MATERIALS AND METHODS}

This study was carried out on 32 (64 sides) dried specimens of human atlas (C1) vertebrae of unknown age and sex from the Department of Anatomy, Velammal Medical College, Madurai, Tamil Nadu. The superior articular facets were studied for variability in shape due to presence of constriction and partial or complete separation of facets. Superior articular facet of the study vertebra was measured, using Vernier calliper and any abnormalities present in it were noted down and photographed. All the measurements were recorded bilaterally, in millimetres. All study specimens (vertebrae) were inspected to ensure that they were intact and free from osteophytes or metastatic tumours before measurements were made.

\section{Inclusion Criteria}

Intact human atlases from the dissected cadavers.

\section{Exclusion Criteria}

1. Broken, undeveloped and porous atlas vertebrae were excluded from the study.

2. Macerated bones were also excluded from the study.

Each atlas vertebra was inspected for the constrictions on the margins of the facets whether it was on medial margin, lateral margin or on both margins along with study of symmetry. Grooves of facets were inspected for its shallow or deepness; divisions of facets were dependent on morphology of grooves.

Divisions and shapes were studied according to presence of constrictions and grooves, when constrictions were on one margin either medial or lateral, it was considered as kidney shaped.

When facets were notched at multiple sides, it was considered as irregular shape.

When constrictions were present on one margin and grooves were absent, that was considered as Non-division. Kidney, Oval and irregular shapes were defined in nondivision type of superior articular facet. When constrictions were present on both margins along with deep groove, it was considered as complete division and presence of symmetry was also studied.

When constrictions were present on both margins and grooves were shallow, it was considered as incomplete division which was forming two shapes, figure of 8 shaped and dumb-bell shaped. When constrictions were present on both margins of facets, far apart from each other and specially a groove was present connecting these constrictions, considered as 8 shaped. When constrictions were present on both margins approaching the centre of facets, the shape of SAF was considered dumb-bell shaped.[3]

Depth of facets was also studied, when it was shallow it was considered as flat and when it was deep it was considered as concave. The facets which were notched at multiple sides were considered as irregular in shape.

Maximum Antero-posterior Diameter (length) of superior articular facet: Two points were taken, one on the anterior limit of SAF and other on its posterior limit, then length was measured (in $\mathrm{mm}$ ) along its principal axis directed anteromedially.
Maximum Transverse Diameter (width) of superior articular facet: Two points were taken, one on the medial limit of SAF and other on its lateral limit, then width was measured (in $\mathrm{mm}$ ) perpendicular to the principal axis.

Statistical analyses of the measurements were done.

\section{RESULTS}

\section{Shape of Superior Articular Facet}

Of the 64 superior articular facets which were examined, 26 facets $(40.62 \%)$ were without constrictions i.e. oval shaped (Figure 1). 17 facets (26.56\%) showed a constriction only on one side and were considered as kidney shaped (Figure 2). 5 facets $(7.81 \%)$ showed a constriction on both the sides and far apart along with a groove in the centre of the facet, which were considered as the 'figure of 8' shape (Figure 3). 7 facets $(10.94 \%)$ were found to have a constriction on both the sides with constriction approaching towards the centre of the facet and were labelled as dumb-bell shaped (Figure 4).

Trilobed facet was seen in 3 facets (4.69\%), 2 on right side and 1 on left side of three atlas vertebrae (Figure 2).

When there were constrictions on both the margins and grooves were deep, division was complete. In our study, 2 facets $(3.12 \%)$ of two different vertebrae, one on right side and other on left side showed complete separation of facet into two parts with a gap in between (Figure 4) upper facets were quadrangular and lower facets were triangular.

Two atlas vertebrae with irregular superior articular facet showed ridge in the centre (6.24\%) (Figure 5). The sidewise distribution of shapes of superior articular facet is shown in Table 1. Depending on depth, SAF were either concave or flat. Concave facets were more, $65 \%$ on both the sides. Flat facets were observed in $35 \%$ on both the sides.

\section{Size of Superior Articular Facet}

Observed and measured values of superior articular facet (SAF) were as below:

On right side, average length was $20.3 \pm 3.12 \mathrm{~mm}$ and breadth was $11.7 \pm 1.15 \mathrm{~mm}$.

On left side, the average length was $21 \pm 2.16 \mathrm{~mm}$ and breadth was $11.05 \pm 1.11 \mathrm{~mm}$.

Average size of superior articular facet showing complete separation was $11.3 \mathrm{~mm}$ x $9.1 \mathrm{~mm}$ and $10.2 \mathrm{~mm}$ x $8.6 \mathrm{~mm}$ with a gap of $5.1 \mathrm{~mm}$.

\begin{tabular}{|c|c|c|c|c|c|}
\hline \multirow{2}{*}{ Shape } & \multicolumn{3}{|c|}{ Side of SAF } & \multicolumn{2}{c|}{ Total sides } \\
\cline { 2 - 6 } & Bilateral & $\begin{array}{c}\text { Right } \\
\text { Side }\end{array}$ & $\begin{array}{c}\text { Left } \\
\text { Side }\end{array}$ & Number & $\%$ \\
\hline Oval & 9 & 4 & 4 & 26 & 40.62 \\
\hline Kidney & 4 & 4 & 5 & 17 & 26.56 \\
\hline Dumb bell & - & 3 & 4 & 7 & 10.94 \\
\hline $\begin{array}{c}\text { Figure } \\
\text { of eight }\end{array}$ & - & 3 & 2 & 5 & 7.81 \\
\hline Trilobed & - & 2 & 1 & 3 & 4.69 \\
\hline $\begin{array}{c}\text { Complete } \\
\text { separation }\end{array}$ & - & 1 & 1 & 2 & 3.12 \\
\hline Irregular & 2 & - & - & 4 & 6.24 \\
\hline $\begin{array}{r}\text { Table 1. Sidewise Distribution of Various Shapes of } \\
\text { Superior Articular Facet (SAF) (N=64) }\end{array}$ \\
\hline
\end{tabular}




\begin{tabular}{|c|c|c|c|c|c|c|}
\hline $\begin{array}{l}\text { Shape } \\
\text { of SAF }\end{array}$ & $\begin{array}{l}\text { Manjunath \& } \\
\text { Ranganath[5] } \\
\quad \text { N = } 100\end{array}$ & $\begin{array}{c}\text { Lalit } \\
\text { et al[6] } \\
N=60\end{array}$ & $\begin{array}{c}\text { Ashita } \\
\text { et al[7] } \\
\mathrm{N}=\mathbf{1 0 0}\end{array}$ & $\begin{array}{c}\text { Kintu } \\
\text { et al[8] } \\
\mathbf{N}=\mathbf{2 0 0}\end{array}$ & $\begin{array}{c}\text { Girish \& } \\
\text { Shishir }{ }^{[9]} \\
\text { N = 200 }\end{array}$ & $\begin{array}{l}\text { Present Study } \\
\qquad N=64\end{array}$ \\
\hline Oval & $33(33 \%)$ & $17(28.33 \%)$ & $31(31 \%)$ & $76(38 \%)$ & $53(26.5 \%)$ & $26(40.62 \%)$ \\
\hline Kidney & $10(10 \%)$ & $12(20 \%)$ & $18(18 \%)$ & $45(22.5 \%)$ & $19(9.5 \%)$ & $17(26.56 \%)$ \\
\hline Dumb bell & - & $21(35 \%)$ & $24(24 \%)$ & $51(25.5 \%)$ & 85 (42.5\%) & 7 (10.94\%) \\
\hline Figure of eight & $18(18 \%)$ & $10(16.67 \%)$ & $13(13 \%)$ & - & $20(10 \%)$ & $5(7.81 \%)$ \\
\hline Trilobed & - & - & - & - & - & $3(4.69 \%)$ \\
\hline $\begin{array}{c}\text { Complete } \\
\text { separation }\end{array}$ & - & - & $9(9 \%)$ & - & - & $2(3.12 \%)$ \\
\hline Triangular & - & - & - & - & $23(11.5 \%)$ & - \\
\hline Elongated & - & - & - & $28(14 \%)$ & - & - \\
\hline Irregular & 39 (39\%) & - & - & - & - & $4(6.24 \%)$ \\
\hline \multicolumn{7}{|c|}{ Table 2. Showing the Frequency (in percentage) of Shapes of Superior } \\
\hline
\end{tabular}

\begin{tabular}{|c|c|c|c|c|c|c|}
\hline \multirow{2}{*}{$\begin{array}{l}\text { Shape of Superior } \\
\text { Articular Facet }\end{array}$} & \multicolumn{6}{|c|}{ Authors with Superior Articular Facet (SAF); N-Total Number Facet } \\
\hline & $\begin{array}{c}\text { Side of } \\
\text { SAF }\end{array}$ & $\begin{array}{l}\left.\text { Lalit et al }{ }^{6]}\right] \\
2011 N=60\end{array}$ & $\begin{array}{l}\text { Ashita et al[7] } \\
2016 \mathrm{~N}=100\end{array}$ & $\begin{array}{c}\text { Kintu et al[8] } \\
2013 \mathrm{~N}=200\end{array}$ & $\begin{array}{c}\text { Girish }{ }^{[9]} \\
2014 \mathrm{~N}=200\end{array}$ & $\begin{array}{c}\text { Present study } \\
\text { N }=64\end{array}$ \\
\hline \multirow{2}{*}{ Oval } & Right & 10 & 17 & 37 & 29 & 13 \\
\hline & Left & 7 & 14 & 39 & 24 & 13 \\
\hline \multirow{2}{*}{ Kidney } & Right & 6 & 8 & 26 & 7 & 7 \\
\hline & Left & 6 & 10 & 19 & 12 & 10 \\
\hline \multirow{2}{*}{ Dumb Bell } & Right & 11 & 13 & 23 & 44 & 3 \\
\hline & Left & 10 & 11 & 28 & 41 & 4 \\
\hline \multirow{2}{*}{ Figure of Eight (8) } & Right & 3 & 6 & - & 10 & 3 \\
\hline & Left & 7 & 7 & - & 10 & 2 \\
\hline \multirow{2}{*}{ Trilobed } & Right & - & - & - & - & 2 \\
\hline & Left & & & - & & 1 \\
\hline \multirow{2}{*}{ Complete Separation } & Right & - & 5 & - & - & 1 \\
\hline & Left & & 4 & 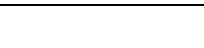 & & 1 \\
\hline \multirow{2}{*}{ Irregular } & Right & - & - & - & - & 2 \\
\hline & Left & - & - & - & - & 2 \\
\hline \multirow{2}{*}{ Triangular } & Right & - & - & - & 10 & - \\
\hline & Left & - & - & - & 13 & - \\
\hline \multirow{2}{*}{ Elongated } & Right & - & - & 14 & - & - \\
\hline & Left & - & - & 14 & - & - \\
\hline Table & mpari. & Superior $A l$ & Ir Facet with ot & uthors in relc & to Shape and & \\
\hline
\end{tabular}

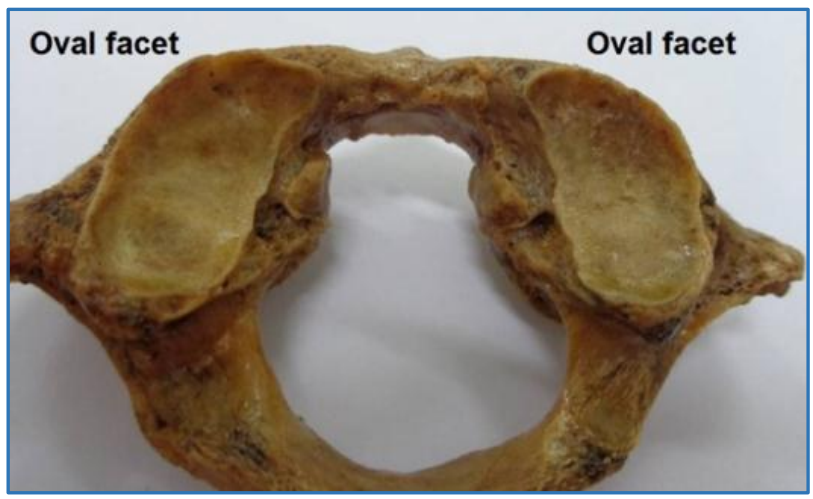

Figure 1. Oval Superior Articular Facet on both Sides

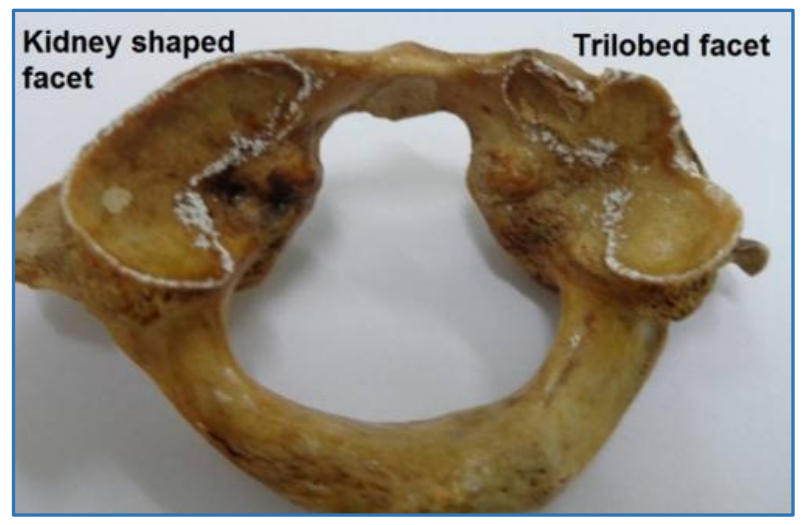

Figure 2. Kidney Shaped \& Trilobed Facet 


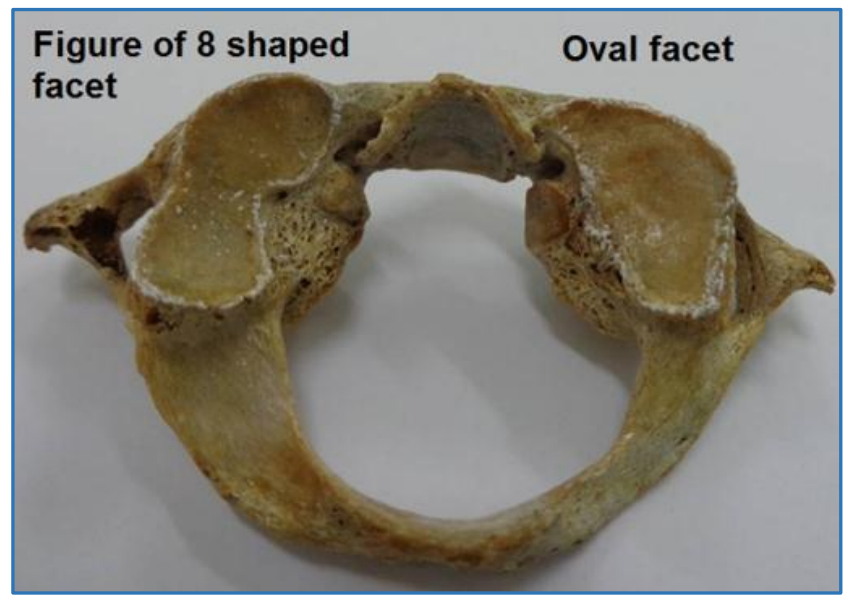

Figure 3. Figure of 8 Shape \& Oval Shape of Superior Articular Facet

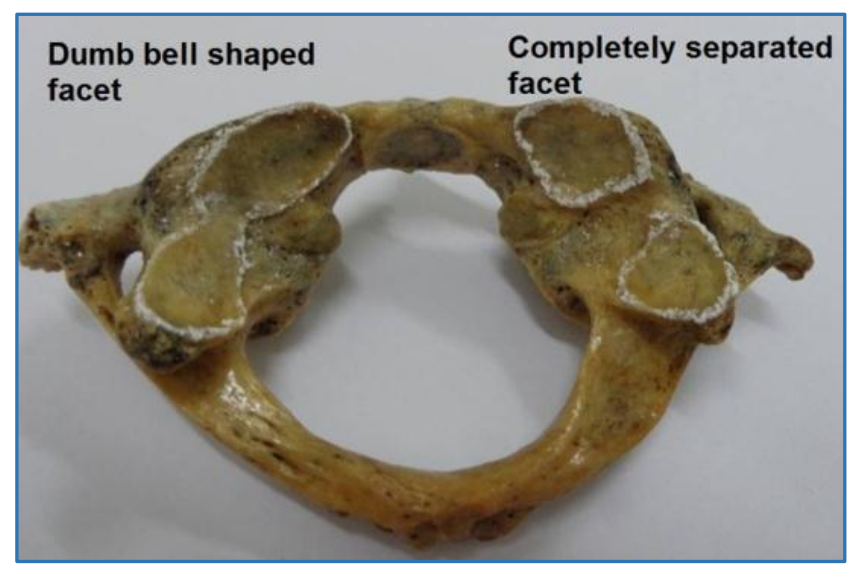

Figure 4. Dumb bell shaped Facet on Left Side and Completely Separated Facet on Right Side

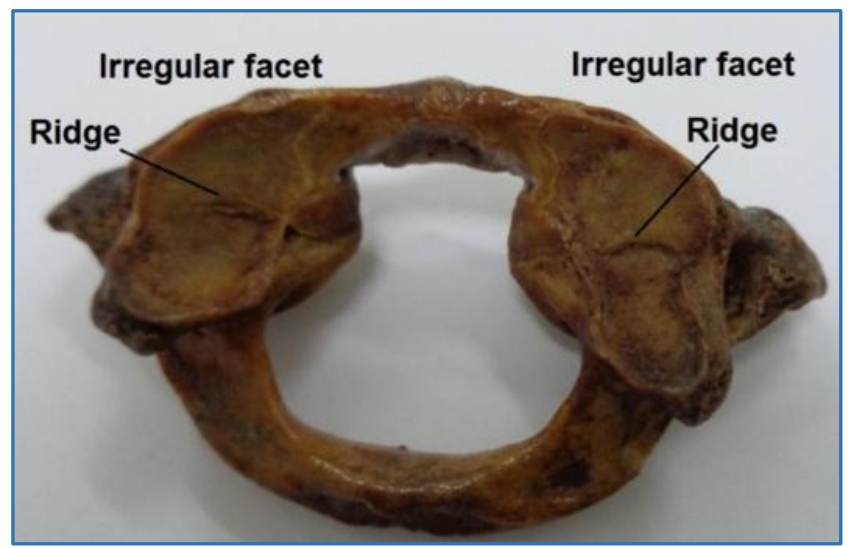

Figure 5. Irregular Facet with Ridge on both sides

\section{DISCUSSION}

Injuries of the upper cervical spine which cause severe disabilities following trauma have always been an interesting focus for anatomists.[4] Superior articular facets which are present on the atlas vertebrae face superomedially and are well known for nodding movements and furthermore for the weightbearing of the head. These are also known for the reception of the condyles of the occipital bone to form an atlanto-occipital joint. The wide variation in the morphometric parameters of superior articular facets like the asymmetry, constrictions along the margins, shapes, sizes and separations of facets were reported in the literature. The large number of variations seen in the shape, size and depth of the superior articular facets of the atlas vertebrae indicate that the atlanto-occipital joint is correspondingly variable.

\section{Shape of Superior Articular Facet}

In our study, the oval shape (40.62\%) of the superior articular facet (SAF) was the most commonly observed shape, which was succeeded by kidney $(26.56 \%)$, dumb bell shape (10.94\%) and figure of 8 shape (Table 1 \& 2; Figure 1-5). Similar to our study, Kintu et al[8] (38\%) and Ashita et al[7] (31\%) also reported oval shape of the superior articular facet (SAF) as the most commonly observed shape, but in their report oval shape of SAF was succeeded by dumb bell shape and kidney shape. Girish[9] (42.5\%) and Lalit et al[6](35\%) reported dumb bell as the most commonly observed shape (Table 2). In contrast to the present study where we observed irregular shape only in $6.24 \%$ of SAF, Manjunath \& Ranganath[5] observed irregular facet (39\%) as the most common shape of SAF which was followed by oval shape $(33 \%)$. Completely separated bilobed SAFs were observed in $3.12 \%$ of our study SAFs which is lesser than the findings of $\mathrm{S}$ Singh ${ }^{[3]}$ (5.5\%) and Ashita et al[ ${ }^{[6]}$ (9\%). An uncommon shape of SAF i.e tri-lobed SAF was observed in $4.69 \%$ of the current study SAFs. Gupta et al[10] has also mentioned the trilobed SAF in $4.3 \%$ of their study specimen.

While considering the sidewise distribution of SAF in the present study, oval-shaped facets were equally distributed in both sides each having 13 facets but in other comparative studies, oval shape was more common on the right side. Kintu et. $\mathrm{al}^{[8]}$ reported oval shaped SAFs were more common on the left side. Kidney-shaped SAFs were more on the left side in our findings which matches with the findings of Ashita et al[7] and Girish \& Shishir, [9] but this shape was more common on the right side as per report of Kintu et al..[8] According to the study report of Lalit et al,[6] kidney-shaped SAFs were equally distributed in both sides each having 6 SAFs (Table 3). SAFs with dumb bell shape were more common in the left side in the present study which matches the report of Kintu et al[8] but as per study reports of Lalit et al,[6] Ashita et al[7] and Girish \& Shishir, ${ }^{[9]}$ right side dominates over left side.

The superior articular facet of the atlas with a different shape i.e. an oval kidney, dumb bell shape, is also an indication of the further restriction of the movements at the atlanto-occipital joint.[6]

\section{Size of Superior Articular Facet}

In the present study, average size of superior articular facet (SAF) was approx. the same on both sides. The anteroposterior diameter (length) of superior articular facet of atlas was found to be $20.3 \mathrm{~mm}$ on the right side and $21 \mathrm{~mm}$ on the left side. The transverse diameter (breadth) of superior articular facet of atlas was found to be $11.7 \mathrm{~mm}$ on the right side and $11 \mathrm{~mm}$ on the left side. As compared to our finding- right side (length: breadth $=20.3 \mathrm{~mm}: 11.7 \mathrm{~mm}$ ) and left side (length: breadth $=21 \mathrm{~mm}: 11 \mathrm{~mm}$ ), slightly higher average size with similar tendency was reported by Gupta et al[10] on both sides- right side (length: breadth $=21.5 \mathrm{~mm}$ : $11.8 \mathrm{~mm}$ ) and left side (length: breadth $=21.8 \mathrm{~mm}: 11.5 \mathrm{~mm}$ ). Ashita et al[7] also reported their findings higher than oursright side (length: breadth $=21.33 \mathrm{~mm}: 11.53 \mathrm{~mm}$ ) and left side (length: breadth $=21.37 \mathrm{~mm}: 11.72 \mathrm{~mm}$ ). 
In completely separated bilobed SAF, two lobes were separated by $5.1 \mathrm{~mm}$ which matches with the finding of $\mathrm{S}$ Singh ${ }^{[3]}$ where he mentioned, in some cases of the completely separated facets are $5 \mathrm{~mm}$ apart. Asymmetry of SAF was the common finding in the present study. G Paraskevas et al[11] reported an increase in the incidence of separation of SAF and that a decrease in constrictions could possibly be the result of a restriction in the atlanto-occipital motion in old age.

\section{CONCLUSION}

The study of SAFs of human atlas vertebrae showed different shapes. The most commonly observed shape was oval shape, followed by kidney shape, dumb bell and figure of eight shape. Completely separated bilobed SAFs were observed in $3.12 \%$ of our study SAFs. No vertebra showed symmetrical facets. The knowledge of these measurements and the variations present may be of importance to understand the ergonomics of the craniovertebral joint, useful for anatomists in enhancing their teaching skills and helpful for orthopaedic surgeons, neurosurgeons, clinicians and radiologists in dayto-day clinical practice.

\section{REFERENCES}

[1] William M, Newell RLM, et al. The back: cervical vertebrae. In: Standring S, Ellis H, Haely JC, et al. eds. Gray's Anatomy. 39th edn. Edinburg, London: Elsevier Churchill Livingstone 2005:742-6.

[2] Suchomel P, Choutka O, Barsa P. Surgical anatomy. In: Suchomel P, Choutka O. eds. Reconstruction of upper cervical spine and craniovertebral junction. Springer Heidelberg Dordrecht London New York: 2011;5-7. DOI 10.1007/978-3-642-13158-5
[3] Singh S. Variations of the superior articular facets of atlas vertebrae. Journal of Anatomy 1965;99(Pt 3):56571.

[4] Bohlman HH. Acute fractures and dislocations of the cervical spine. An analysis of three hundred hospitalized patients and review of the literature. J Bone and Joint Surgery 1979;61(8):1119-42.

[5] Motagi MV, Ranganath V. Morphometric analysis of superior articular facets of atlas vertebra and its clinical applications in ergonomics of atlanto-occipital joints. Journal of Clinical and Diagnostic Research 2013;7(12):2674-6.

[6] Lalit M, Piplani S, Kullar JS, et al. The morphological analysis of the superior articular facet of the adult human atlas vertebra. Journal of Clinical and Diagnostic Research 2011;5(2):274-7.

[7] Kaore A, Kamdi AU, Kasote AP, et al. A study of morphometry of superior articular facet of atlas and its clinical implication in central India. Int J Anat and Res 2016;4(3):2750-6.

[8] Vyas K, Joshi H, Dave M, et al. Variation in superior articular facets of atlas vertebrae in terms of its morphology. NJIRM 2013;4(1):12-15.

[9] Patil GV, Shishir Kumar. Superior articular facets of atlas vertebra - a morphological study. International Journal of Science and Research 2014;3(7):364-5.

[10] Gupta C, Radhakrishnan P, Palimar V, et al. A quantitative analysis of atlas vertebra and its abnormalities. Journal of Morphological Science 2013;30(2):77-81.

[11] Paraskevas G, Papaziogas B, Tzaveas A, et al. Morphological parameters of the superior articular facets of the atlas and potential clinical significance. Surg Radiol Anat 2008;30(8):611-7. 